\title{
EFFECT OF SITAGLIPTIN ON GLYCEMIC CONTROL AND BEYOND - IN PATIENTS WITH TYPE 2 DIABETES MELLITUS
}

\author{
RAMYA RAVICHANDAR ${ }^{1 *}$, ARAVIND ANAPATHOOR NAGARAJAN ${ }^{2}$ \\ ${ }^{1}$ Department of Pharmacology, Sree Balaji Medical College and Hospital, Chromepet, Chennai, Tamil Nadu, India. ${ }^{2}$ Consultant \\ Diabetologist, Rajalakshmi Diabetes Center, Kancheepuram, Tamil Nadu, India. Email: dr.ramyaravichandar@gmail.com
}

Received: 03 April 2018, Revised and Accepted: 04 May 2018

\begin{abstract}
Objective: The objective of the study was to assess the pleiotropic effects of Sitagliptin as add-on therapy to the conventional antidiabetic drugs.

Methods: This was designed as a prospective study. 140 patients with type 2 diabetes mellitus (T2DM) whose glycated hemoglobin (HbA1c) was $>7 \%$ despite receiving education on diet and exercise and/or medications were enrolled in this study. Sitagliptin (100 mg) was administered once a day orally for 6 months as an add-on therapy with the conventional antidiabetic drugs. The outcome of the therapy was assessed on the level of improvement in the fasting plasma glucose, postprandial plasma glucose, HbA1c levels, lipid profile, body mass index, blood pressure, and albuminuria in the third and $6^{\text {th }}$ month when compared to the first visit.
\end{abstract}

Results: After 6 months of treatment with Sitagliptin, fasting blood glucose levels significantly reduced (202.6 \pm 49.21 to $186.1 \pm 50.14$, p=0.029) as well as HbA1c $(9.5 \pm 1.27$ to $9.1 \pm 1.28, \mathrm{p}=0.016)$. There was a statistically significant $(\mathrm{p}<0.001)$ reduction of blood pressure, cholesterol, and urinary albumin-creatinine ratio progressively.

Conclusion: Sitagliptin has a significant effect on lipid profile, blood pressure and albuminuria in addition to its effect on blood glucose profile and HbA1c without many side effects, in patients with T2DM.

Keywords: Diabetes mellitus, Sitagliptin, Pleiotropic, Blood pressure, Albuminuria, Lipid profile.

(C) 2018 The Authors. Published by Innovare Academic Sciences Pvt Ltd. This is an open access article under the CC BY license (http://creativecommons. org/licenses/by/4. 0/) DOI: http://dx.doi.org/10.22159/ajpcr.2018.v11i8.26066

\section{INTRODUCTION}

Diabetes mellitus is a group of metabolic diseases characterized by hyperglycemia resulting from defects in insulin secretion, insulin action, or both [1]. The International Diabetes Federation assesses the total number of diabetic subjects to be 425 million people, in 2017, in comparison with 50.8 million in 2010 [2]. In urban areas of Tamil Nadu, diabetes prevalence was higher in people with lower socioeconomic status [3]. Over the past 30 years, the status of diabetes has transformed from a mild disorder of the aged to one of the most important causes of mortality and morbidity for the youth and middle-aged people [4]. The greater part of diabetes mellitus falls into two wide etiopathogenetic classes. In one class, type 1 diabetes, there is an absolute deficiency of insulin secretion. Individuals at risk of developing type 1 diabetes can frequently be identified by the serological testimony of an autoimmune process taking place in the pancreatic islets and also by genetic markers. In the other, much more common class, type 2 diabetes, the cause is a combination of insulin resistance and an inadequate compensatory insulin secretory response. The basis of the derangement in carbohydrate, protein, and fat metabolism in diabetes is the insufficient action of insulin on target tissues. Deficient insulin action results from insufficient secretion of insulin and/or weakened tissue responses to insulin at points in the pathways of insulin action. Loss of first-phase insulin secretion and diminished second-phase secretion are the typical features of type 2 diabetes mellitus (T2DM); and it is recognized that a reduction in the first-phase of insulin secretion is seen in impaired glucose tolerance and the initial stage of T2DM $[5,6]$. Symptoms of marked hyperglycemia consist of polydipsia, polyuria, loss of weight, and occasionally with polyphagia and blurred vision. Life-threatening acute complications of uncontrolled diabetes are nonketotic hyperosmolar syndrome or hyperglycemia with ketoacidosis. Diabetes can be diagnosed by the presence of symptoms of diabetes with random plasma glucose concentration $\geq 200 \mathrm{mg} / \mathrm{dl}$ or fasting plasma glucose $\geq 126 \mathrm{mg} / \mathrm{dl}$ on 2 occasions or $2 \mathrm{~h}$ plasma glucose during oral glucose tolerance test $\geq 200 \mathrm{mg} / \mathrm{dl}$ or glycated hemoglobin $(\mathrm{HbA} 1 \mathrm{c}) \geq 6.5 \%[7]$.

Long-term complications of diabetes include nephropathy leading to renal failure; peripheral neuropathy with the hazard of foot ulcers, amputations, and Charcot joints; retinopathy with potential loss of vision and autonomic neuropathy leading to gastrointestinal, cardiovascular and genitourinary symptoms, and sexual dysfunction. Diabetic patients have a greater incidence of atherosclerotic peripheral arterial, cardiovascular, and cerebrovascular disease. Abnormalities of lipoprotein metabolism and hypertension are frequently seen in patients with diabetes.

The salient feature of diabetic nephropathy is albuminuria, which can be screened by the measurement of urine albumin to creatinine ratio in a random spot sample. It includes both microalbuminuria $(30-299 \mathrm{mcg} / \mathrm{mg}$ creatinine) and macroalbuminuria $(\geq 300 \mathrm{mcg} / \mathrm{mg}$ creatinine) [8]. The incidence of microalbuminuria is about $25.5 \%$ in T2DM patients [9].

The treatment of T2DM includes the use of various drugs in the first line of management which may result in a progressive decline in $\beta$ cell function. Currently available oral antidiabetic drugs include insulin secretagogues, insulin sensitizers, and drugs acting by other mechanisms. They are sulfonylureas, meglitinides, biguanides, thiazolidinediones, and alpha-glucosidase inhibitors. They possess adverse effects such as weight gain and hypoglycemia (with sulfonylureas), edema (with thiazolidinediones), and lactic acidosis (with biguanides) and they are restricted for use in renal and hepatic dysfunction. UKPDS has demonstrated that there is a progressive ß-cell failure despite treatment with the above drugs [10]. Hence, the perfect antidiabetic drug must delay or reverse the cell decline, which can be 
used concomitantly with current drugs, with no additional or serious adverse drug reaction profile, thus minimizing long-term complications and mortality.

The study of incretin hormones and entero-insular axis resulted in the discovery of two groups of antidiabetic agents - the glucagon-like peptide 1 (GLP-1) analogs and the dipeptidyl peptidase IV (DPP-IV) inhibitors [11]. Oral delivery of glucose produces a greater release of insulin as compared to intravenous glucose. Glucose-dependent insulinotropic polypeptide and GLP-1 are released from the intestines and enhance glucose-dependent insulin secretion. These hormones are named incretins. GLP-1 considerably augments glucose-dependent insulin secretion and subsequently has become a striking target for therapeutic development in type 2 DM [12]. GLP-1 also reduces glucagon secretion, slows gastric emptying, and decreases appetite. Thus, it reduces postprandial glucose excursions and also induces weight loss. Counteracting these advantages, circulating GLP-1 is rapidly inactivated by the DPP-IV within 1-2 min [13]. Hence, the goal of therapy is to inactivate the DPP-IV enzyme, thus increasing endogenous GLP-1 levels. Various orally effective DPP-IV inhibitors include Sitagliptin, Vildagliptin, Saxagliptin, Linagliptin, and Teneligliptin, now available for therapy of type 2 diabetes in India.

Sitagliptin is the prototype and the first approved member of DPP- IV inhibitor class. It is a potent, highly selective, reversible, and competitive inhibitor of DPP-IV enzyme. It was approved by the US Food and Drug Administration in 2006. It has a half-life of $12.4 \mathrm{~h}$ and is given as $100 \mathrm{mg}$ tablet once daily. It can be used as monotherapy or add on to metformin/sulfonylureas/pioglitazone/insulin. Adverse effects are nasopharyngitis, headache, and hypoglycemia when used with sulfonylureas. Hence, while combining with a sulfonylurea, the dose of sulfonylurea should be reduced to $50 \%$ to minimize the risk of hypoglycemia. It has high patient compliance rate due to its advantage of once-daily dosing. Dose adjustment of Sitagliptin is required in moderate and severe renal impairment. Sitagliptin has many advantages over other DPP-IV inhibitors. Sitagliptin is well tolerated and can be given once daily in contrast to Vildagliptin, which may cause hepatotoxicity and is given twice daily. There are also no interactions with other drugs which are an advantage over Saxagliptin. It has been shown that chronic Sitagliptin treatment resolved the metabolic derangement, hypertriglyceridemia, inflammation, reduced the severity of the pancreatic endocrine, and exocrine lesions and corrected hypertension [14]. Hence, we chose Sitagliptin for our present study.

\section{Objective}

The objective of this study was to determine the pleiotropic effects of Sitagliptin as add-on therapy to the conventional antidiabetic drugs. Primary endpoints were a reduction in HbA1c and reduction of fasting and postprandial blood glucose. Secondary endpoints were a reduction of cholesterol levels, reduction of systolic and diastolic blood pressure, reduction of albuminuria, and reduction of body mass index (BMI).

\section{MATERIALS AND METHODS}

Institutional Ethics Committee approved this study (Ethics clearance No. 566/IEC/2014), and informed consent was obtained from all participants. Patients with T2DM (age $\geq 18$ years) whose HbA1c was $>7 \%$ despite receiving education on diet and exercise and/ or medications were enrolled in this study. The sample size was estimated as 140 using the formula, with the precision error of 5\%, type 1 error of $5 \%$, and $10 \%$ attrition [15]. The exclusion criteria were a history of hypersensitivity to any DPP-4 inhibitor, renal dysfunction (serum creatinine: male $\geq 1.5 \mathrm{mg} / \mathrm{dl}$ and female $\geq 1.3 \mathrm{mg} / \mathrm{dl}$ ), serum triglyceride (TGL) levels $>300 \mathrm{mg} / \mathrm{dL}$, pregnancy, lactation, and females of childbearing potential. For the study subjects, Sitagliptin was given either as a new prescription or as an add-on to conventional antidiabetic drugs. Before entering the study, 9 patients had been treated only with diet and exercise. 54 patients had been receiving glimepiride, which was reduced to $2 \mathrm{mg}$ /day or less on entry. Moreover, the dose of glimepiride was reduced to half or stopped when HbA1c was reduced by $>0.5 \%$ by the next visit. Metformin ( $\mathrm{n}=72)$ and Pioglitazone $(\mathrm{n}=33)$ that patients had been taking before this study commenced, were continued throughout the study without any change in the dosing. 48 patients were taking Angiotensin II receptor blockers, and 10 patients were taking HMG-CoA reductase inhibitors (statins); both of these were continued throughout the study without dose modification. Sitagliptin $100 \mathrm{mg}$ was administered orally once daily for 6 months.

\section{Clinical measurements}

Physical examination (including measurement of blood pressure and BMI) and laboratory tests such as fasting and postprandial blood glucose, HbA1c, total cholesterol (TC), TGLs, high-density lipoprotein, low-density lipoprotein, very low-density lipoprotein, and urinary albumin creatinine ratio (ACR) were performed at the starting point, 3 months, and 6 months after starting treatment with Sitagliptin.

Plasma glucose estimation was done using glucose oxidase-peroxidase (POD) method. HbA1c estimation was done using high-performance liquid chromatography method. TC was estimated using cholesterol oxidase and POD enzymatic colorimetric method. TGL estimation was done by the enzymatic glycerol phosphate oxidase and POD method. High-density lipoprotein (HDL), cholesterol estimation was performed by direct immunoinhibition method. Low-density lipoprotein (LDL) and very low-density lipoprotein (VLDL) were calculated using the formulae:

LDL=TC-HDL-(TGL/5) and VLDL=TGL/5.

Spot urinary ACR was estimated using immunoturbidimetry.

\section{Baseline characteristics}

A total of 140 patients were enrolled into this study, of whom130 (51 males and 79 females) with a mean age of 53.8 years were successfully followed over 6 months of Sitagliptin treatment.

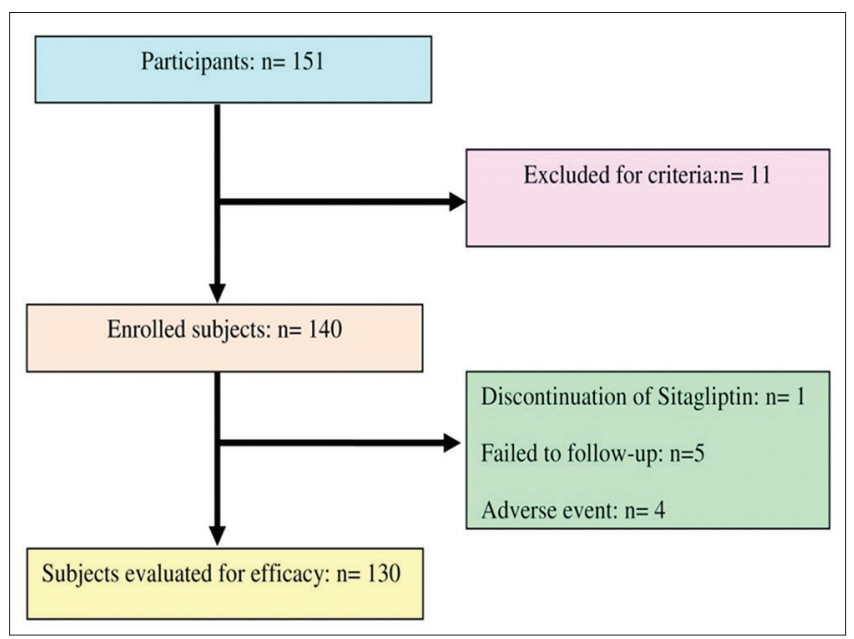

Fig. 1: Study enrolment

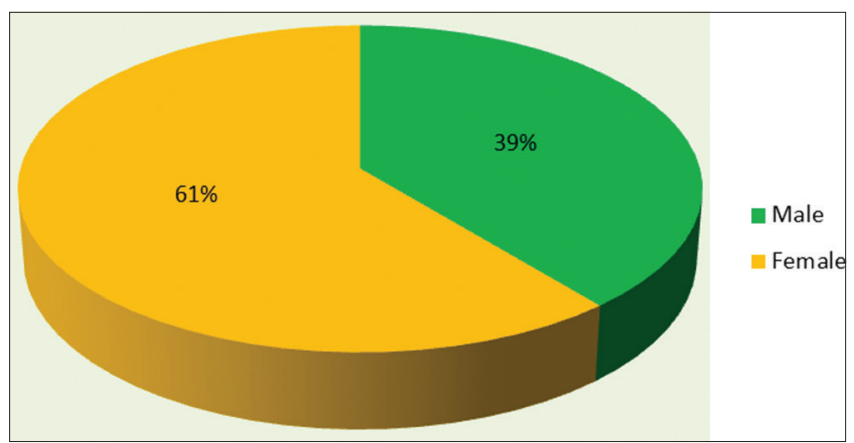

Fig 2: Sex distribution 
Mean BMI was $26.5 \pm 2.44 \mathrm{~kg} / \mathrm{m}^{2}$ and mean duration of diabetes was $9.5 \pm 4.8$ years among these 130 patients at the beginning of the study.

\section{Statistical methods}

Statistical analysis was done using Statistical Package for the Social Sciences. All data measurements were at least on an interval scale. Hence, the descriptive statistics (mean, standard deviation, median, minimum, and maximum values) as applicable were described using frequency tables. Paired t-test was used to test differences between mean values between three different time points taking two-points at a time. Oneway ANOVA was employed to test for overall differences between all three time-points together. Box-plots were drawn to pictorially depict the scenarios of each variable at three different time points.

\section{RESULTS AND DISCUSSION}

\section{Effect of Sitagliptin on glycemic control}

In our study, the mean reduction in fasting blood glucose between the three visits was 9.3 (Visit 1 vs. Visit 2), 7.6 (Visit 2 vs. Visit 3), and 16.5 (Visit 1 vs. Visit 3 ) which was statistically significant ( $\mathrm{p}=0.029)$.

Table 1: Age distribution according to the sex

\begin{tabular}{lll}
\hline Age (years) & Sex & \\
\cline { 2 - 3 } & Male & Female \\
\hline Mean \pm SD & $54.4 \pm 9.85$ & $53.1 \pm 10.76$ \\
Range & & \\
Minimum & 31 & 27 \\
Maximum & 72 & 75 \\
\hline
\end{tabular}

SD: Standard deviation
The mean reduction in postprandial blood glucose (PPBG) between the three visits was 10.7 (Visit 1 vs. Visit 2), 6.9 (Visit 2 vs. Visit 3), and 17.6 (Visit 1 vs. Visit 3) which was statistically insignificant $(p=0.074)$. The mean reduction in HbA1c between the three visits was 0.3 (Visit 1 vs. Visit 2), 0.1 (Visit 2 vs. Visit 3), and 0.4 (Visit 1 vs. Visit 3) which was also statistically significant $(\mathrm{p}=0.016)$ (Fig. 3 and Table 2).

Our results were similar to those of previous studies reported in the United States of America and Japan [16,17]. Nathan et al. reported that the estimated decrease in HbA1clevels is $1-2 \%$ with metformin monotherapy, $1-2 \%$ with sulfonylureas, $0.5-1.4 \%$ with thiazolidinediones, $0.5-1 \%$ with meglitinides, $0.5-0.8 \%$ with $\alpha$-glucosidase inhibitors, and $0.5 \%-0.8 \%$ with DPP-IV inhibitors [18].

However, metformin is associated with gastrointestinal side effects; sulfonylureas are associated with hypoglycemic episodes and thiazolidinediones with cardiac failure, which is not associated with the utilization of DPP-IV inhibitors $[17,19]$.

Although mild side effects such as diarrhea were seen in 3 patients and 1 patient had nasopharyngitis, they were self-limiting and quite manageable. None of the patients experienced hypoglycemia with Sitagliptin.

Effects of Sitagliptin on lipid profile and blood pressure

In our study TGL, LDL, and TC progressively decreased between the visits; reduction in TGL was not statistically significant $(p=0.14)$, whereas the reduction in TC and LDL was statistically significant ( $p=0.05 \mathrm{TC}, \mathrm{p}=0.008 \mathrm{LDL}$ ). Moreover, there was a statistically significant

Table 2: Effect of Sitagliptin on various parameters measured at baseline, $3^{\text {rd }}$ month, and $6^{\text {th }}$ month of treatment

\begin{tabular}{|c|c|c|c|c|c|c|c|c|}
\hline \multirow[t]{2}{*}{ S. No. } & \multirow[t]{2}{*}{ Parameter } & \multicolumn{3}{|l|}{ Mean \pm SD } & \multicolumn{4}{|l|}{$p$ value } \\
\hline & & Visit 1 & Visit 2 & Visit 3 & Overall & $\begin{array}{l}\text { Visit } 1 \text { versus } \\
\text { Visit } 2\end{array}$ & $\begin{array}{l}\text { Visit } 1 \text { versus } \\
\text { Visit } 3\end{array}$ & $\begin{array}{l}\text { Visit } 2 \text { versus } \\
\text { Visit } 3\end{array}$ \\
\hline 1 & Fasting blood glucose & $202.6 \pm 49.21$ & $193.3 \pm 49.78$ & $186.1 \pm 50.14$ & 0.029 & $<0.001$ & $<0.001$ & $<0.001$ \\
\hline 2 & Postprandial blood glucose & $283.3 \pm 62.29$ & $272.6+61.95$ & $265.7 \pm 2.31$ & 0.074 & $<0.001$ & $<0.001$ & $<0.001$ \\
\hline 3 & Glycated hemoglobin & $9.5 \pm 1.27$ & $9.2 \pm 1.25$ & $9.1 \pm 1.28$ & 0.016 & $<0.001$ & $<0.001$ & $<0.001$ \\
\hline 4 & Systolic blood pressure & $126.8 \pm 5.89$ & $125.4 \pm 5.6$ & $123.4+5.44$ & $<0.001$ & $<0.001$ & $<0.001$ & $<0.001$ \\
\hline 5 & Diastolic blood pressure & $81.5 \pm 4.23$ & $80.1+4.09$ & $78.8 \pm 4.18$ & $<0.001$ & $<0.001$ & $<0.001$ & $<0.001$ \\
\hline 6 & Body mass index & $26.5 \pm 2.44$ & $26.4 \pm 2.47$ & $26.2 \pm 2.49$ & 0.0738 & $<0.001$ & $<0.001$ & $<0.001$ \\
\hline 7 & $\begin{array}{l}\text { Urine albumin creatinine } \\
\text { ratio }\end{array}$ & $159.2 \pm 124.65$ & $135 \pm 110.78$ & $114 \pm 99.48$ & 0.005 & $<0.001$ & $<0.001$ & $<0.001$ \\
\hline 8 & Total cholesterol & $178.7 \pm 34.05$ & $173.1 \pm 32.89$ & $168.6 \pm 32.56$ & 0.05 & $<0.001$ & $<0.001$ & $<0.001$ \\
\hline 9 & Triglycerides & $145.1 \pm 49.91$ & $135.5 \pm 47.42$ & $127.8 \pm 45.88$ & 0.14 & $<0.001$ & $<0.001$ & $<0.001$ \\
\hline 10 & High-density lipoprotein & $31.7 \pm 7.76$ & $34.5+7.33$ & $37.1 \pm 7.58$ & $<0.001$ & $<0.001$ & $<0.001$ & $<0.001$ \\
\hline 11 & Low-density lipoprotein & $118 \pm 31.78$ & $111.8 \pm 30.93$ & $105.9 \pm 31.11$ & 0.008 & $<0.001$ & $<0.001$ & $<0.001$ \\
\hline 12 & $\begin{array}{l}\text { Very low-density } \\
\text { lipoprotein }\end{array}$ & $28.7 \pm 10.2$ & $26.8 \pm 9.51$ & $25.2 \pm 9.14$ & 0.016 & $<0.001$ & $<0.001$ & $<0.001$ \\
\hline
\end{tabular}

SD: Standard deviation
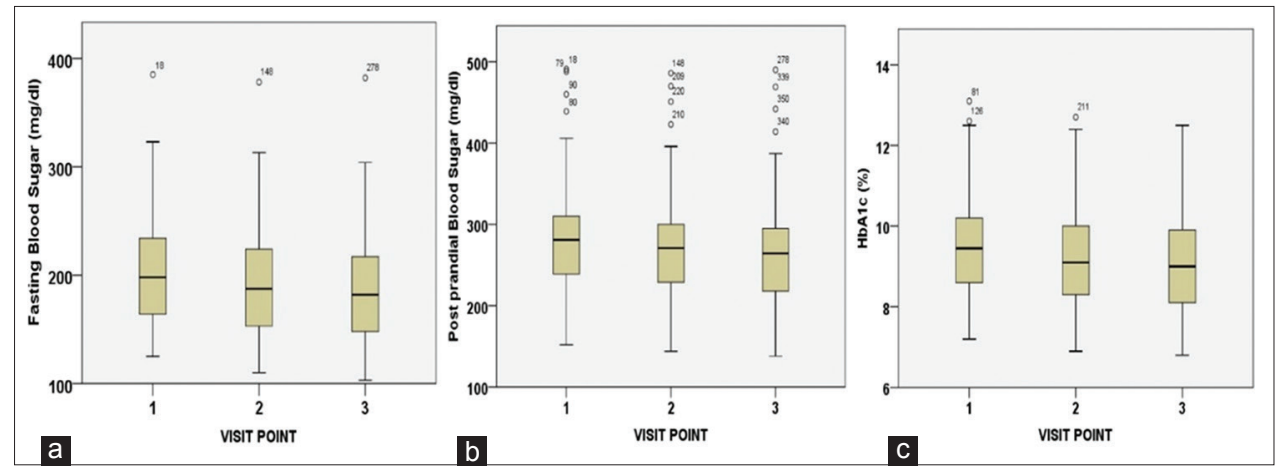

Fig. 3: Box-plot showing serial changes at baseline, $3^{\text {rd }}$ month, and 6 th month (depicts median, $1^{\text {st }}$ and $3^{\text {rd }}$ quartile, minimum and maximum values with outliers identified). (a) Fasting plasma glucose (FPG). (b) Postprandial plasma glucose (PPBG). (c) Glycated hemoglobin (HbA1c) 
$(\mathrm{p}<0.001)$ rise in HDL cholesterol between the three visits in our study, which is cardioprotective (Fig. 4 and Table 2).

Qin et al. showed that GLP-1 reduces the intestinal lymphatic flow and also reduces TGL absorption and production of apo B and apo AIV in rats [20]. Prolonged DPP-4 inhibition alters the genes essential for fatty acid oxidation, including acyl-coenzyme dehydrogenase medium chain and Acyl-CoA synthetase. In addition, DPP-IV inhibitors decrease the levels of hepatic mRNA transcripts for acetyl coenzyme A acyltransferase 1 and carnitine palmitoyltransferase 1 [21]. Because these modulations are based on incretin receptor actions, Sitagliptin may have the ability to decrease the levels of TC and TGL.

There was a statistically significant $(\mathrm{p}<0.001)$ reduction of both systolic and diastolic blood pressure in a progressive manner between the three

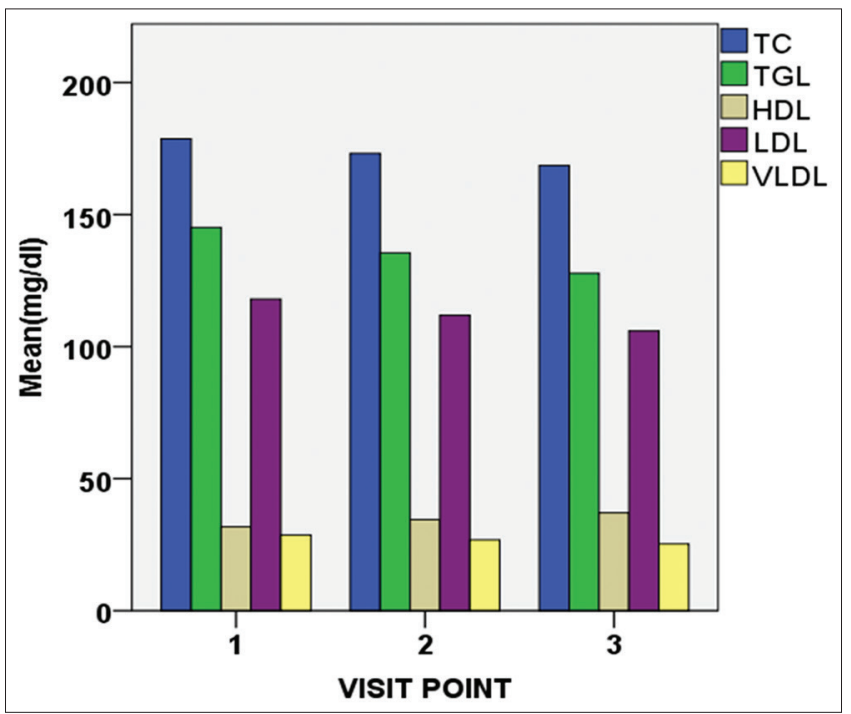

Fig. 4: Serial changes in lipid profile at baseline, $3^{\text {rd }}$ month, and $6^{\text {th }}$ month (TC: Total cholesterol, TGL: Triglycerides, HDL: Highdensity lipoprotein, LDL: Low-density lipoprotein, and VLDL: Very low-density lipoprotein) visits in our study (Fig. 5 and Table 2). GLP-1 demonstrates vascular effects through GLP-1 receptor signaling [22]. In addition, a metabolite of GLP-1 has vasodilator properties independent of the GLP-1 receptor in nitric oxide/ cyclic guanosine monophosphate-dependent manner [22]. DPP-4 inhibitors amplify the levels of GLP-1, probably leading to vasodilatation and reduction of blood pressure. GLP-1 also increases the excretion of sodium in the proximal renal tubule in insulin-resistant obese persons. Therefore, GLP1-induced amplification in urinary sodium excretion might also contribute to the reduction of blood pressure after Sitagliptin treatment [23].

\section{Effect of Sitagliptin on albuminuria}

In our study, there was a statistically significant $(p=0.005)$ reduction of albuminuria (urinary ACR) progressively during the three visits (Fig. 5 and Table 2). One of the mechanisms of albuminuria reduction might be the initiation of reasonable blood glucose control. Sitagliptin reduces glucose fluctuation by reducing fasting and PPBG which might inhibit vascular inflammation [24].

Increased active GLP-1 levels also could inhibit vascular inflammation which accounts for another mechanism. It has been reported that GLP-1 inhibits upregulation of VCAM-1 mRNA levels in the endothelial cells of blood vessels, induced by advanced glycation end products, at concentrations which Sitagliptin treatment has been shown to reach [25]. GLP-1 receptor was proven to be present on endothelial cells of the human umbilical vein, and its presence was confirmed in human glomerular endothelial cells also. Thus, Sitagliptin may exert an antiinflammatory effect in the kidney through GLP-1 receptor by augmenting active GLP-1, causing the decrease of albuminuria. The anti-inflammatory effect of GLP-1 by the involvement of the cyclic AMP/Protein Kinase A pathway may also contribute to reducing albuminuria [26].

\section{Effect of Sitagliptin on BMI}

Although it has been proved in many studies that DPP-IV inhibitors are neutral on weight, our study showed there was a mild, statistically insignificant $(\mathrm{p}=0.07)$ reduction in BMI progressively (Fig. 5 and Table 2) [27].

\section{LIMITATIONS OF THE STUDY}

Since this was a non-randomized study, the pleiotropic effects of Sitagliptin as add-on therapy were not clearly derived. To know the
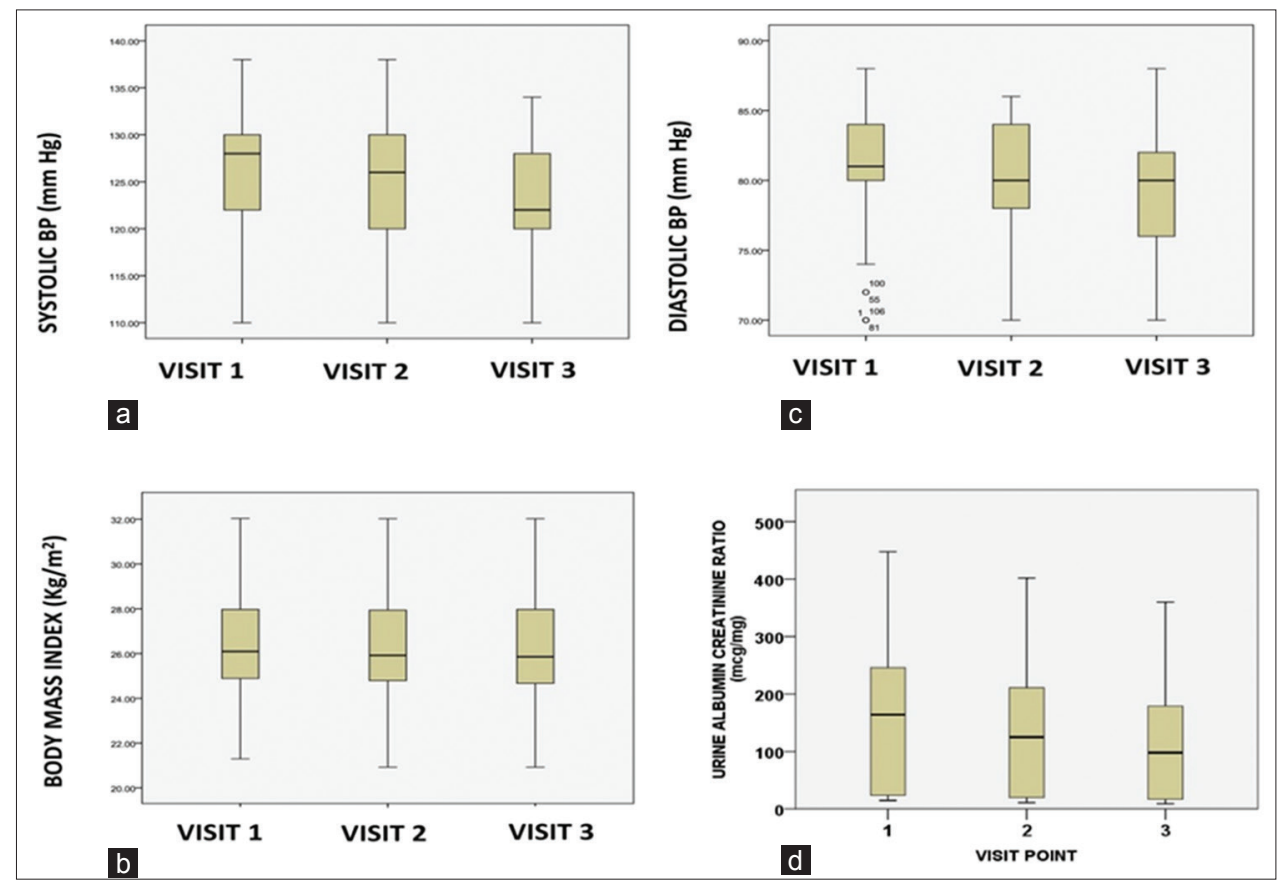

Fig. 5: Effect of Sitagliptin on (a) systolic blood pressure, (b) diastolic blood pressure, (c) body mass index, and (d) urine albumincreatinine ratio (Visit 1 - baseline, Visit $2-3^{\text {rd }}$ month, and Visit 3-6 $6^{\text {th }}$ month) 
unbiased effects of Sitagliptin, a randomized multicentric doubleblinded control study with Sitagliptin in one arm and placebo in another arm along with conventional antidiabetic drugs in both the groups can be done in the future. Furthermore, the drug is very expensive, which puts the affordability of all the patients into question.

\section{CONCLUSION}

The clinical use of the DPP-4 inhibitor Sitagliptin has beneficial effects not only on blood glucose control but also for improving blood pressure, lipid profile, and albuminuria in addition to a high rate of adherence to treatment.

\section{AUTHORS' CONTRIBUTION}

All authors have made significant contributions to the research work in the manuscript. Dr. Ramya Ravichandar: Conception and designing of the study, collection, analysis, and interpretation of data, background search for a review of literature, critical revision of the article, and final approval of the study to be published. Dr. A.N. Aravind: Conception of the study, drafting the manuscript, critical revision of the article, and final approval of the study to be published.

\section{CONFLICTS OF INTEREST}

All authors have none to declare.

\section{REFERENCES}

1. American Diabetes Association. Diagnosis and classification of diabetes mellitus. Diabetes Care 2010;33 Suppl 1:S62-9.

2. International Diabetes Federation. IDF Diabetes Atlas. $8^{\text {th }}$ ed. Brussels, Belgium: International Diabetes Federation; 2017. Available from: http://www.diabetesatlas.org.

3. Anjana RM, Deepa M, Pradeepa R, Mahanta J, Narain K, Das HK, et al. Prevalence of diabetes and prediabetes in 15 states of india: Results from the ICMR-INDIAB population-based cross-sectional study. Lancet Diabetes Endocrinol 2017;5:585-96.

4. Mohan V, Sandeep S, Deepa R, Shah B, Varghese C. Epidemiology of type 2 diabetes: Indian scenario. Indian J Med Res 2007;125:217-30.

5. Cerasi E, Luft R. The plasma insulin response to glucose infusion in healthy subjects and in diabetes mellitus. Acta Endocrinol (Copenh) 1967;55:278-304.

6. Davis SN, Piatti PM, Monti L, Brown MD, Branch W, Hales CN, et al. Proinsulin and insulin concentrations following intravenous glucose challenges in normal, obese, and non-insulin-dependent diabetic subjects. Metabolism 1993;42:30-5.

7. Ahmed SJ, Masood AR, Sumana S, Ghori KA, Ansari JA, Khan M. Stroke outcomes in nondiabetic, denovo diabetic and diabetic Indian patients measured by modified Rankin scale: An observational study. Int J Pharm Pharm Sci 2017;9:94-7.

8. Krolewski AS, Niewczas MA, Skupien J, Gohda T, Smiles A, Eckfeldt JH, et al. Early progressive renal decline precedes the onset of microalbuminuria and its progression to macroalbuminuria. Diabetes Care 2014;37:226-34

9. Kanakamani J, Ammini AC, Gupta N, Dwivedi SN. Prevalence of microalbuminuria among patients with type 2 diabetes mellitus - a hospital-based study from north India. Diabetes Technol Ther 2010;12:161-6.

10. UK Prospective Diabetes Study Group. Intensive blood-glucose control with sulphonylureas or insulin compared with conventional treatment and risk of complications in subjects with Type 2 diabetes (UKPDS 33). Lancet 1998;352:837-53.

11. Desai A, Tandon N. Management of Type 2 diabetes mellitus with oral antihyperglycaemic therapy. Natl Med J India 2007;20:192-8.

12. Kabul RE, Kabul E, Pratiwi A, Setiawan A, Dahlan K, Kartono A. Mathematical model of glucose-insulin system using the modified oral minimal model and the Incretin effects. Int $\mathrm{J}$ Pharm Pharm Sci 2015;7:451-4.

13. Seino Y, Fukushima M, Yabe D. GIP and GLP-1, the two incretin hormones: Similarities and differences. J Diabetes Investig 2010;1:8-23.

14. Ferreira L, Teixeira-de-Lemos E, Pinto F, Parada B, Mega C, Vala H, et al. Effects of Sitagliptin treatment on dysmetabolism, inflammation, and oxidative stress in an animal model of Type 2 diabetes (ZDF Rat). Mediators Inflamm 2010;2010:1-11.

15. Charan J, Biswas T. How to calculate sample size for different study designs in medical research? Indian J Psychol Med 2013;35:121-6.

16. Aschner P, Kipnes MS, Lunceford JK, Sanchez M, Mickel C, WilliamsHerman DE, et al. Effect of the dipeptidyl peptidase-4 inhibitor sitagliptin as monotherapy on glycemic control in patients with type 2 diabetes. Diabetes Care 2006;29:2632-7.

17. Nonaka K, Kakikawa T, Sato A, Okuyama K, Fujimoto G, Kato N, et al. Efficacy and safety of sitagliptin monotherapy in japanese patients with type 2 diabetes. Diabetes Res Clin Pract 2008;79:291-8.

18. Nathan DM, Buse JB, Davidson MB, Ferrannini E, Holman RR, Sherwin $\mathrm{R}$, et al. Medical management of hyperglycemia in Type 2 diabetes: A consensus algorithm for the initiation and adjustment of therapy: A consensus statement of the American diabetes association and the European association for the study of diabetes. Diabetes Care 2009;32:193-203.

19. Singh S, Loke YK, Furberg CD. Thiazolidinediones and heart failure: A teleo-analysis. Diabetes Care 2007;30:2148-53.

20. Qin X, Shen H, Liu M, Yang Q, Zheng S, Sabo M, et al. GLP-1 reduces intestinal lymph flow, triglyceride absorption, and apolipoprotein production in rats. Am J Physiol Gastrointest Liver Physiol 2005;288:G943-9.

21. Flock G, Baggio LL, Longuet C, Drucker DJ. Incretin receptors for glucagon-like peptide 1 and glucose-dependent insulinotropic polypeptide are essential for the sustained metabolic actions of vildagliptin in mice. Diabetes 2007;56:3006-13.

22. Ban K, Noyan-Ashraf MH, Hoefer J, Bolz SS, Drucker DJ, Husain M, et al. Cardioprotective and vasodilatory actions of glucagon-like peptide 1 receptor are mediated through both glucagon-like peptide 1 receptordependent and -independent pathways. Circulation 2008;117:2340-50.

23. Gutzwiller JP, Tschopp S, Bock A, Zehnder CE, Huber AR, Kreyenbuehl M, et al. Glucagon-like peptide 1 induces natriuresis in healthy subjects and in insulin-resistant obese men. J Clin Endocrinol Metab 2004;89:3055-61.

24. Horváth EM, Benko R, Kiss L, Murányi M, Pék T, Fekete K, et al. Rapid 'glycaemic swings' induce nitrosative stress, activate poly(ADPribose) polymerase and impair endothelial function in a rat model of diabetes mellitus. Diabetologia 2009;52:952-61.

25. Ishibashi Y, Matsui T, Takeuchi M, Yamagishi S. Glucagon-like peptide-1 (GLP-1) inhibits advanced glycation end product (AGE)induced up-regulation of VCAM-1 mRNA levels in endothelial cells by suppressing AGE receptor (RAGE) expression. Biochem Biophys Res Commun 2010;391:1405-8.

26. Dozier KC, Cureton EL, Kwan RO, Curran B, Sadjadi J, Victorino GP, et al. Glucagon-like peptide-1 protects mesenteric endothelium from injury during inflammation. Peptides 2009;30:1735-41.

27. Amori RE, Lau J, Pittas AG. Efficacy and safety of incretin therapy in Type 2 diabetes: Systematic review and meta-analysis. JAMA 2007;298:194-206. 